\title{
Sustainable Use of Steel Industry Slag (SIS) for Concrete Production: A State Art of Review
}

\author{
Md. Muzammel Hoque', Md. Arif Hossen ${ }^{2 *}$ \\ ${ }^{1}$ Department of Business Administration, Southern University Bangladesh, Chattogram, Bangladesh \\ ${ }^{2}$ Center for Environmental Science \& Engineering Research, Chittagong University of Engineering \& Technology, \\ Chattogram, Bangladesh \\ Email: engrmuzammel@gmail.com, *arifhossen0101@gmail.com
}

How to cite this paper: Hoque, Md.M. and Hossen, Md.A. (2019) Sustainable Use of Steel Industry Slag (SIS) for Concrete Production: A State Art of Review. Open Journal of Applied Sciences, 9, 841-850. https://doi.org/10.4236/ojapps.2019.912067

Received: November 4, 2019

Accepted: December 9, 2019

Published: December 12, 2019

Copyright $\odot 2019$ by author(s) and Scientific Research Publishing Inc. This work is licensed under the Creative Commons Attribution International License (CC BY 4.0).

http://creativecommons.org/licenses/by/4.0/

\begin{abstract}
This paper presents a review on the sustainable use of steel industry slag (SIS) in the construction industry for sustainable development. This issue also may contribute significantly to attain the sustainable development goal (SDG). If feasible sector is not determined earlier for the use of SIS for the country like Bangladesh then the unproductive uses will be increased and as well without large-scale utilization, direct dumping of SIS will create environmental hazards. On the other hand, the sustainable use of SIS in concrete production can contribute to the economic growth of the country; in addition, it can also contribute to keeping our natural environment safe from hazardous pollution. Another observation of this study is SIS used in cement and concrete production as aggregate or as additional cementing materials has a long-term strength and durability. Besides, replacement of cement with SIS deferred the hydration reaction at early ages, without any significant troubles. Furthermore, it can also be mentioned that high replacement of SIS with cement may raise a problem of volume instability which can be solved by using ground-granulated blast-furnace slag (GGBS) as combined admixture and the slump problem of concrete mixtures can be adjusted with addition of copper slag or class F fly ash. Feasibility analysis of SIS usage and an awareness program for all the stakeholders may be implemented for the sustainable uses of SIS. Both of these will play a vital role to safeguard environment in addition to economic growth of the country.
\end{abstract}

\section{Keywords}

Cement, Developing Country, Sustainable Development, Construction

\section{Introduction}

For sustainable development in the construction industry, steel slag has been 
used as a substitute for cement in concrete. Steel slag is a byproduct from steel making industry [1] characterized by variable chemical components and low cementitious properties. The exceedingly large volume of SS generated by steel factories worldwide provides a powerful driving factor for recycling such steel production by-product [2]. Recycling of SS, however, could be handy as long as the materials provided have good durability and retain properties in line with standards specifications after long aging [3]. The steel slag used in cement and concrete production as aggregate or as additional cementing materials has a significant positive impact on environment due to its long-term strength and durability [4] [5]. For the sustainable development, large-scale utilization of SS is crucial because of its massive production, which will create environmental hazards if it is dumped directly.

In this context, the construction industry can play an important role. In the present situation, SIS has not yet reached a high level of utilization in country like Bangladesh. Possible reason behind this is the lack of research about how to use this steel industry byproduct. However, high levels of utilization of SIS in some developed countries making some hopes and lessons for developing countries like Bangladesh. Therefore, adequate research works should be done in Bangladesh in the aspect of sustainable uses of SIS. In addition, it is also needed to find a method for recycling SIS as a more highly valued material, specifically to ensure its potential use as an admixture in concrete production.

\section{Statement of the Problem}

Bangladesh is a developing country. Huge construction works are going on in the whole country. As a result, day by day demand for steel as well as concrete is increasing tremendously. The steel industries are producing significant quantities of waste i.e., SIS. Bangladesh's overall steel production is estimated at 8 million tons per year and slag production is estimated at around 120,000 to 160,000 tons per year [6]. But it is not being used properly that means there have no sustainable use of this SIS in Bangladesh. But in the modern society, prior effort must be provided for waste reuse and recycling which also important in environmental aspect [7]. The various uses of SIS are already identified by the different research works. But for sustainable use of SIS in concrete production have been investigated in the limited number of studies to date. So, it is very essential to find out the way for sustainable use of SIS in concrete production. Because this SIS being used in different purposes unwisely. So, this study will help to establish an argument in favor of sustainable use of steel industry slag for concrete production.

\section{Literature Review}

There is not enough literature relating to sustainable use of steel industry slags for concrete production in context of Bangladesh. However, the following studies mostly related to use of steel industry slag's in foreign context have been 
critically reviewed in order to build up the strong foundation of the existing study, as far as possible.

Lee et al. (2019) [8] have examined the prospect of using electric arc furnace (EAF) oxidizing slag as the binder. The study performed a relative evaluation of the mechanical properties of concrete containing electric arc furnace oxidizing slag, steel-making slag, and granulated blast furnace (GBF) slag. The study showed that replacing cement with EAF oxidizing slag deferred the hydration reaction at early ages, without any significant troubles in setting time, strength or shrinkage development.

Zhang et al. (2019) [9] has studied the consequence of microstructure, hydration behavior, volume and mechanical properties together with the evaluation of the environmental performance of UHPC mixes containing steel slag. It is found that the early age hydration is delayed when cement is partially change by SS in UHPC mixes, leading to decrease in the compressive strength. It is also observed that addition of SS does not vary the pattern of autogenous shrinkage development while the autogenous shrinkage strain is a slight reduced at a higher SS content.

Liu and Guo (2018) [10] have investigated the fluidity and non-evaporable water content. The study found that the fluidity of the paste containing SS is high and the non-evaporable water content of the hardened paste containing SS powder is close to the control sample at late ages. It is also observed that SS powder and SS aggregate both react and be connected tightly to hardened paste and gels, respectively.

Palod, G.D. et al. (2017) [4] has investigated the potential uses of SS in concrete as cementitious material. This study showed that high replacement of Basic Oxygen Furnace (BOS) steel slag along with GGBS has a very encouraging outcome. The study also revealed that the problem of volume instability due to free $\mathrm{CaO}$ and $\mathrm{MgO}$ can be solved by using GGBS as combined admixture.

Yüksel (2016) [11] has also observed that volume instability due to free $\mathrm{CaO}$ and $\mathrm{MgO}$ and contaminants such as chromium, lead, and mercury are two fundamental alarming difficulties in increasing the level of usage of SIS in concrete. The high-water absorption capacity of Steel slag aggregate (SSA) as compared with natural aggregate is another difficulty. So, SS needs to be processed before use in the construction industry to resolve the problems which yield extra costs.

The study of [12] on sustainable use of industrial-waste reviewed about the partial replacement of fine aggregate for concrete mixtures. This study observed that there are a number of industrial wastes like foundry sand, steel slag, copper slag, imperial smelting furnace slag (ISF slag), blast furnace slag, coal bottom ash, ferrochrome slag, palm oil clinker etc which may be used as full or partial replacement of coarse aggregate or fine aggregate. This study examined different physical and mechanical properties of industrial waste and industrial waste concrete comparing with natural sand. It is observed that the concrete mixtures where ISF slag, copper slag, class F fly ash is used instead of sand shows enhanced durability and strength properties, but in the case of copper slag, slump 
increases as the rate of replacement increases and in the case of class F fly ash, slump decreases.

Ulubeylia and Artirb (2015) [13] have observed that due to availability of construction waste and blast furnace slag wastes in Turkey, it is suitable to use these wastes in the production of durable concrete, which is also economically and environmentally feasible. This study showed from the investigation that construction waste aggregates and blast furnace slag could be used to develop the mechanical properties, workability, and chemical resistance of the usual concrete mixtures.

Devi and Gnanavel (2014) [14] have investigated the compressive strength, tensile strength, flexural strength and durability tests. The results of investigation indicate that partial replacement of coarse and fine aggregates by steel slag develops the tensile, compressive and flexural strength of conventional concrete. The investigation also observed that mass loss in cubes is very low after concentration in acids and deflection of RCC beams steadily increases due to increase the load on beam. According to ASTM C 1202, the degree of chloride ion penetrability is within limit which indicates the feasibility of usage of SS in concrete.

In the above literature, it is observed that there has not adequate attention for the sustainable use of SS in the concrete production. Detailed study on the use of steel slag process can play an important role in achieving sustainable development in the developing country like Bangladesh.

\section{Details about Steel Industry Slags}

\subsection{Steel Industry Slags}

It is a by-product from steel making process (Figure 1). It is produced during the separation of the molten steel from impurities in steel-making furnaces. The slag occurs as a molten liquid melt and is a complex solution of silicates and oxides that solidifies upon cooling. These slags may be used as either a coarse or
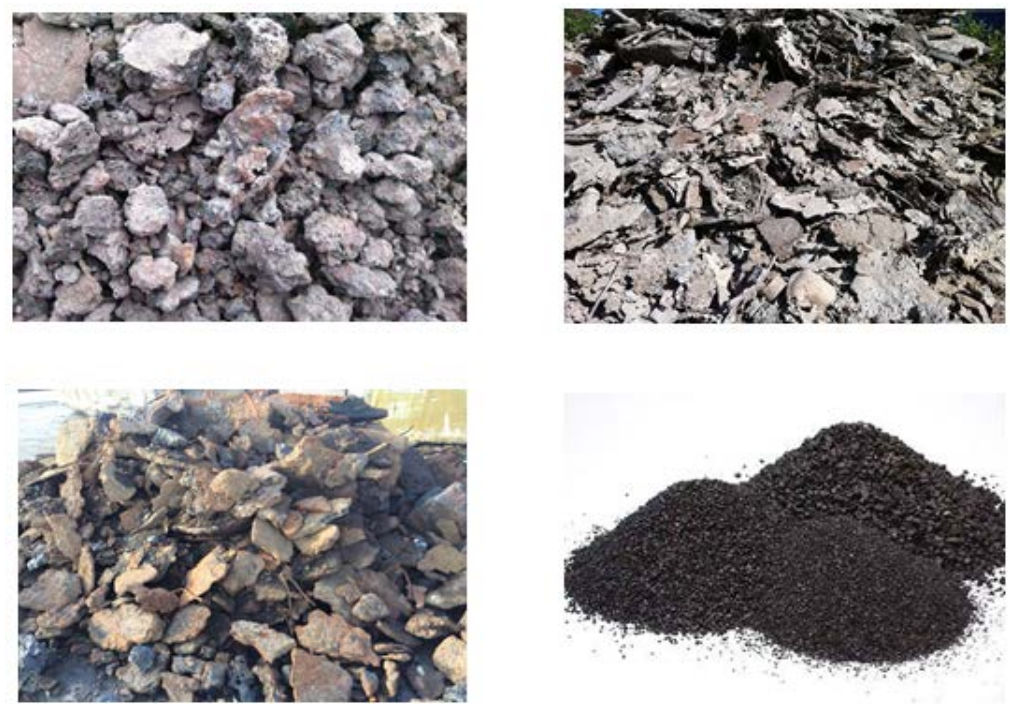

Figure 1. Pictures of steel industry slags. 
fine aggregate for concrete [15] [16]. Due to the high cost of natural sand and the emphasis on sustainable construction, there is a need for the construction industry to search for alternative materials [17]. Table 1 shows the primary characteristics and applications of steel slag.

Figure 2 shows the manufacturing process of steel, where byproduct is slag.

Table 1. Primary characteristics and applications of different types of steel slag. Source: http://www.slg.jp/e/slag/usage.html.

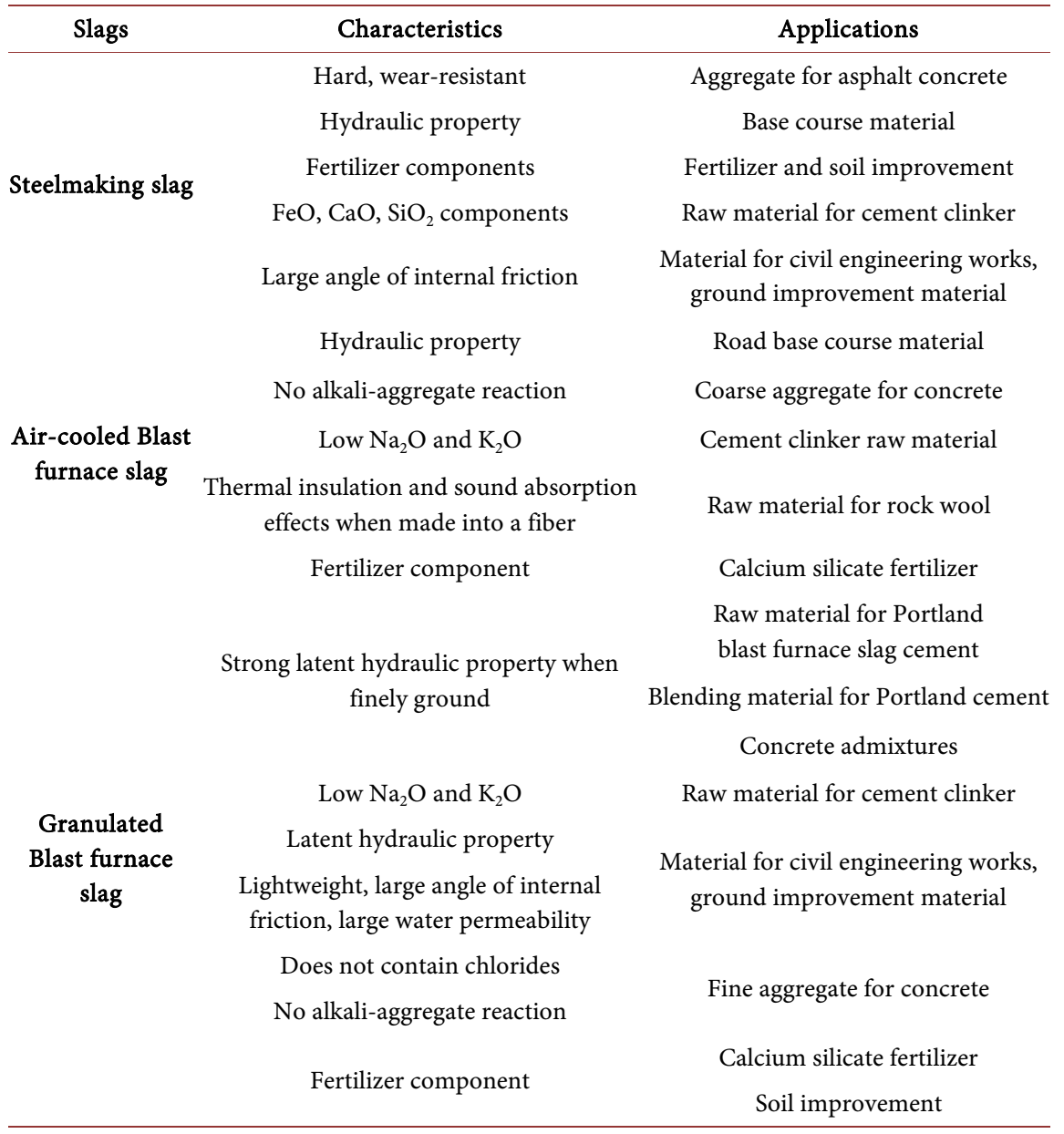

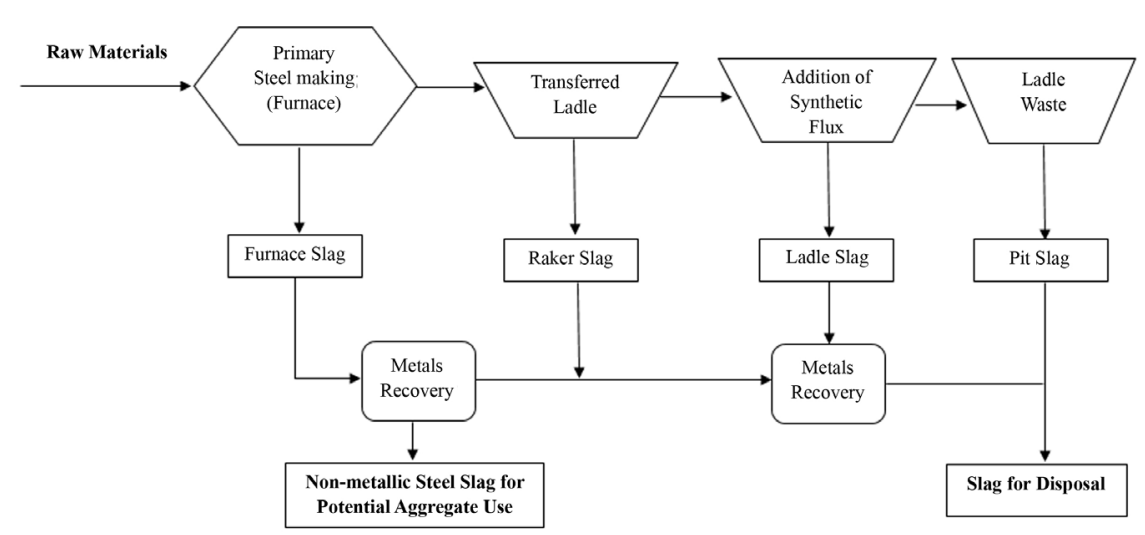

Figure 2. Steel-manufacturing flow chart. 
The operation of the blast furnace and converter prioritizes the composition and temperature of the molten iron and steel, but the composition of the slag is also changed when appropriate, depending on the use of the slag products.

\subsection{The Reactivity of Slag in Cement}

The slag hydration frequency is an important parameter when modeling the cement slag mechanism and simulating the formation of the microstructure [18]. The rate of slag reaction with water is sometimes known as the slag reactivity. The endogenous hydraulic behavior of slag is well known, which means that when the atmosphere is suitable, the slag interacts at a remarkable rate, an alkaline condition in case of building activity [19]. Slag reactivity is the target of numerous studies, and yet is not fully understood. It is understood that several factors contribute to the reactivity of the slag, such as composition of materials, chemical composition, structural properties, temperature, glass structure and alkaline environment [20] (Figure 3). In this section, some of these considerations are discussed, including the chemical composition of the slag, the composition and temperature of the pore solution.

\subsection{Improve Hardened Properties of Concrete by Use of Slag Cement}

Slag cement strengthens many of the strong concrete's strength and toughness properties [22]. Like a pozzolan, it also absorbs calcium hydroxide by-product from Portland cement hydration to form additional CSH. The subsequent cement paste becomes stronger and smoother, strengthening the concrete.

1) Improved compressive and flexural strength,

2) Reduced permeability, and resistance to chloride intrusion and corrosion,

3) Ability to mitigate moderate to severe sulfate attack,

4) Ability to mitigate alkali-silica reaction with reactive aggregates,

5) Reduced thermal stress in mass concrete through lower heat generation.

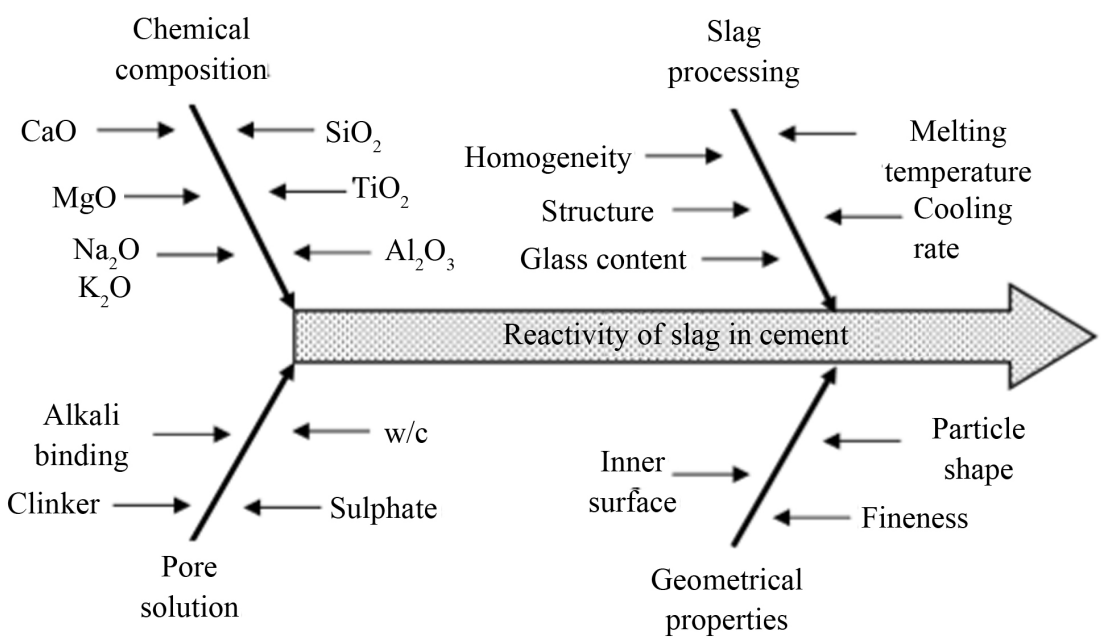

Figure 3. Factors on the reactivity of slag in cement (modified from Olbrich et al. 2001) [21]. 


\subsection{Environmental Benefits of Slag as Partial Replacement of Concrete}

Slag cement processing produces a value-added commodity from a material like blast furnace slag which could otherwise be intended for disposal [23]. In addition to reducing the pressure on landfills by producing slag concrete, it also decreases air pollution at steel plants through the granulation process (as opposed to the conventional air-cooling system). The use of concrete slag cement reduces the impact of construction on the environment by:

1) Reducing greenhouse gas emissions by eliminating approximately one ton of carbon dioxide for each ton of Portland cement replaced.

2) Reducing energy consumption, since a ton of slag cement requires nearly 90\% less energy to produce than a ton of Portland cement.

3) Reducing the amount of virgin material extracted to make concrete.

4) Reducing the "urban heat island" effect by making concrete lighter in color thus reflecting more light and cooling structures and pavements with exposed concrete.

\section{Findings of the Study}

From the review, following conclusions were observed:

1) For the sustainable development, large-scale utilization of steel industry slags (SIS) is crucial because of its massive production, otherwise direct dumping will create environmental hazards.

2) It is very essential to determine feasible sector for the use of SIS in Bangladesh based on the sector wise demand. It is necessary due to resist the unproductive uses of SIS.

3) The sustainable use of SIS in concrete production can contribute to the economic growth of Bangladesh in addition it can contribute to safe our natural environment through reducing $\mathrm{CO}_{2}$ emissions, conserving natural resources and energy savings.

4) The use of SIS as partial replacement of cement improves the microstructure of the concrete as well as its mechanical and hardiness characteristics. Khajuria and Siddique (2014) [24] have affirmed that replacing fine aggregate with SIS in concrete, the compressive strength increases with increase in substitution up to $30 \%$.

5) The SIS usage in cement and concrete production as aggregate or as additional cementing materials has a long-term strength and durability. The Replacement of cement with SIS deferred the hydration reaction at early ages, without any significant troubles in setting time, strength or shrinkage development.

6) High replacement of SIS with cement may raise a problem of volume instability due to presence of free $\mathrm{CaO}$ and $\mathrm{MgO}$ but it can be solved by using ground-granulated blast-furnace slag (GGBS) as combined admixture.

7) The partial replacement of coarse and fine aggregates by SIS develops the 
tensile, compressive and flexural strength of conventional concrete. The mass loss in cubes is very low after concentration in acids and deflection of RCC beams steadily increases due to increase the load on beam. According to ASTM C 1202, the degree of chloride ion penetrability is within limit which indicates the feasibility of usage of SIS in concrete.

8) The replacement of SIS with cement may raise a problem with slump of the concrete which can be adjusted with addition of copper slag or class F fly ash. Replacement of copper slag increases slump and in the case of class F fly ash, slump decreases.

From the analysis of the above findings it can be expressed clearly that there have not any major problems to establish the sustainable use of steel industry slag for concrete production. The small number of insignificant problems which were observed may be overcome through the policy implication stated below.

\section{Conclusion}

In order to achieve sustainable development goal, we must go for the sustainable uses of industrial wastes. Utilization of industrial waste materials in concrete production compensates for the lack of natural resources, solving the disposal difficulty of waste and finding special techniques to safeguard the nature. In this context, the construction industry can play a significant role to make sure the sustainable use of steel industry slags.

\section{Availability of Data and Materials}

All data generated or analyzed during this study were collected from primary and secondary sources.

\section{Funding}

This work was supported by self-funding.

\section{Authors' Contributions}

Md. Muzammel Hoque conceived of the presented idea and Md. Arif Hossen developed the theory and performed the computations. Also, Md. Muzammel Hoque wrote the manuscript with support from Md. Arif Hossen. All authors read and approved the final manuscript.

\section{Acknowledgements}

The authors wish to thank Dr. G M Sadiqul Islam, Professor, Department of Civil Engineering, Chittagong University of Engineering \& Technology for his encouragement.

\section{Conflicts of Interest}

The authors declare they have no competing interests. 


\section{References}

[1] Shi, C. (2004) Steel Slag Its Production, Processing, Characteristics, and Cementitious Properties. Journal of Materials in Civil Engineering, 16, 230-236. https://doi.org/10.1061/(ASCE)0899-1561(2004)16:3(230)

[2] Ness, D., Swift, J., Ranasinghe, D.C., Xing, K. and Soebarto, V. (2015) Smart Steel: New Paradigms for the Reuse of Steel Enabled by Digital Tracking and Modelling. Journal of Cleaner Production, 98, 292-303. https://doi.org/10.1016/j.jclepro.2014.08.055

[3] Wang, G.W. (1992) Properties and Utilization of Steel Slag in Engineering Applications.

[4] Palod, R., Deo, S.V. and Ramtekkar, G.D. (2017) Review and Suggestions on Use of Steel Slag in Concrete and Its Potential Use as Cementitious Component Combined with GGBS. International Journal of Civil Engineering and Technology, 8, 1026-1035.

[5] Maschio, S., Aneggi, E., Fedrizzi, L., Andreatta, F., Lekka, M., Lanzutti, A. and Furlani, E. (2017) Production and Compression Strength of Mortars Containing Unprocessed Waste Powdered Steel Slag. Sustainability, 9, 2372. https://doi.org/10.3390/su9122372

[6] Nieri, M. (2013) IDLC Business Review on Steel Making. European Journal of Oral Implantology, 6, 83-84.

[7] Martinez-Abella, F., Vazquez-Herrero, C. and Perez-Ordonez, J.L. (2012) Properties of Plain Concrete Made with Mixed Recycled Coarse Aggregate. Construction and Building Materials, 37, 171-176. https://doi.org/10.1016/j.conbuildmat.2012.07.045

[8] Lee, J., Choi, J., Yuan, T., Yoon, Y. and Mitchell, D. (2019) Comparing Properties of Concrete Containing Electric Arc Furnace Slag and Granulated Blast Furnace Slag. Materials, 12, 1371. https://doi.org/10.3390/ma12091371

[9] Zhang, S.P. and Zong, L. (2014) Evaluation of Relationship between Water Absorption and Durability of Concrete Materials. Advances in Materials Science and Engineering, 2014, Article ID: 650373. https://doi.org/10.1155/2014/650373

[10] Liu, J. and Guo, R. (2018) Applications of Steel Slag Powder and Steel Slag Aggregate in Ultra-High Performance Concrete. Advances in Civil Engineering, 2018, Article ID: 1426037. https://doi.org/10.1155/2018/1426037

[11] Yüksel, İ. (2017) A Review of Steel Slag Usage in Construction Industry for Sustainable Development. Environment, Development and Sustainability, 19, 369-384. https://doi.org/10.1007/s10668-016-9759-x

[12] Dash, M.K., Patro, S.K. and Rath, A.K. (2016) Sustainable Use of Industrial-Waste as Partial Replacement of Fine Aggregate for Preparation of Concrete: A Review. International Journal of Sustainable Built Environment, 5, 484-516. https://doi.org/10.1016/j.ijsbe.2016.04.006

[13] Ulubeylia, G.C. and Artirb, R. (2015) Sustainability for Blast Furnace Slag: Use of Some Construction Wastes. Procedia-Social and Behavioral Sciences, 195, 2191-2198. https://doi.org/10.1016/j.sbspro.2015.06.297

[14] Devi, V.S. and Gnanavel, B.K. (2014) Properties of Concrete Manufactured Using Steel Slag. Procedia Engineering, 97, 95-104. https://doi.org/10.1016/j.proeng.2014.12.229

[15] Mo, L., Zhang, F., Deng, M., Jin, F.A., Al-Tabbaa and Wang, A. (2017) Accelerated Carbonation and Performance of Concrete Made with Steel Slag as Binding Materials and Aggregates. Cement and Concrete Composites, 83, 138-145. 
https://doi.org/10.1016/j.cemconcomp.2017.07.018

[16] Palankar, N., Shankar, R.A.U. and Mithun, B.M. (2016) Durability Studies on Eco-Friendly Concrete Mixes Incorporating Steel Slag as Coarse Aggregates. Journal of Cleaner Production, 129, 437-448. https://doi.org/10.1016/j.jclepro.2016.04.033

[17] Wei, W., Zhang, W. and Ma, G. (2010) Optimum Content of Copper Slag as a Fine Aggregate in High Strength Concrete. Materials and Design, 31, 2878-2883. https://doi.org/10.1016/j.matdes.2009.12.037

[18] Chen, W. and Brouwers, H.J.H. (2006) The Reaction of Slag in Cement: Theory and Computer Modelling. Proceedings 16th Ibausil, International Conference on Building Materials (Internationale Baustofftagung), Weimar, 20-22 September 2006, 1-445.

[19] Islam, M.M., Islam, M.S., Mondal, B.C. and Islam, M.R. (2010) Strength Behavior of Concrete Using Slag with Cement in Sea Water Environment. Journal of Civil Engineering, 38, 129-140.

[20] Haha, M.B., Lothenbach, B., Le Saout, G. and Winnefeld, F. (2012) Influence of Slag Chemistry on the Hydration of Alkali-Activated Blast-Furnace Slag-Part II: Effect of $\mathrm{Al}_{2} \mathrm{O}_{3}$. Cement and Concrete Research, 42, 74-83. https://doi.org/10.1016/j.cemconres.2011.08.005

[21] Olbrich, E. and Frischat, G.H. (2001) Corrosion of Granulated Glassy Blast Furnace Slags in Aqueous Solutions. Glass Science and Technology, 74, 86-96.

[22] Yi, H., Xu, G., Cheng, H., Wang, J., Wan, Y. and Chen, H. (2012) An Overview of Utilization of Steel Slag. Procedia Environmental Sciences, 16, 791-801. https://doi.org/10.1016/j.proenv.2012.10.108

[23] Jain, M. (2014) Use and Properties of Blast Furnace Slag as a Building Material: A Review. International Journal of Recent Contributions from Engineering, Science \& IT, 2, 54-60. https://doi.org/10.3991/ijes.v2i4.4211

[24] Khajuria, C. and Siddique, R. (2014) Use of Iron Slag as Partial Replacement of Sand to Concrete. International Journal of Science, Engineering and Technology Research, 3, 1877-1880. 